\title{
The Impact of the Learner's Meta-ability Changes on Interpersonal Relations with Teachers under COVID-19: A Lens of Computer-mediated Communication
}

\author{
Soon-jeong Cho ${ }^{1}$, Dong-hyun Lee ${ }^{2}$ \\ ${ }^{1}$ Associate Professor, College of Global Humanities, Sangmyung University, \\ SouthKorea,sj.cho@smu.ac.kr \\ ${ }^{2}$ Adjunct Fellow, Faculty of Design \& Creative Technologies, Auckland University of Technology, \\ NewZealand,don.lee@aut.ac.nz \\ Corresponding author: Dong-hyun Lee
}

\begin{abstract}
During the COVID-19 pandemic, the higher education institutions of South Korea have switched to a full-scale distance-learning paradigm. This study aimed to investigate the impact of changes in the learner's meta-ability on interpersonal relations with teachers as well as to examine a causal relationship between the two variables, along with a theoretical lens of computer-mediated communication (CMC). Relying on media richness theory and social information process theory about $\mathrm{CMC}$, the research first mapped out 16 pre-determined variables from the related literature in a proposed conceptual model combining three measurable elements of meta-abilities required for higher education learners and the learner-teacher relationship. In response to the changeover to online education, this empirical work looked into nonverbal messages from 117 students and surveyed 207 students attending a Korean general university after collecting the data in December 2020 and June 2021 over the two academic terms. Empirical results from the survey respondents showed that the changes in metacognitive ability and meta-affective ability affected interpersonal relations with teachers; however, changes in meta-social ability left no influences on the learner-teacher relationship. The factor in their school year worked as a moderator, particularly affecting the causal relationship in variables between changes with meta-cognition as well as meta-affection and interpersonal relations. These findings would be noteworthy for university educators and policymakers to understand the impact of the learner's metaability changes on interpersonal relations with teachers via CMC in the long-term pandemic context. This study proposes the original CMC-specific theoretical model, and it will eventually contribute to higher education academia and to the field of education informatics whose research interests include rising issues of a distance-learning scenario under COVID-19.
\end{abstract}

Keywords: Computer-mediated, Communication, Meta-ability, Interpersonal Relations, DistanceLearning, Education, Coronavirus Disease 2019 (COVID-19)

\section{Introduction}

Higher education learners are required to improve their meta-ability and establish a close relationship with teachers[1][2]. Competencies for learners in universities have been traditionally infused in the faceto-face (FtF) education environment[3][4]. With the ongoing COVID-19 pandemic, a large majority of higher education institutions in South Korea have switched to a full-scale online education mode since

Received: July 04, 2021; $1^{\text {st }}$ Review Result: August 20, 2021; $2^{\text {nd }}$ Review Result: October 07, 2021 Accepted: November 30, 2021 
early 2020. Before the COVID-19 era, university students had little encountered such a long, dramatic changeover that replaces classroom settings. With an outbreak of COVID-19, many Korean researchers swiftly focused on reporting the practices and trends in distance-learning, analyzing the responses to the online education environment around learners[5][6], and describing the roles and challenges in technology for the 'untact' education services[7][8].

Distance-learning relies on computer-mediated communication (CMC). During learning and after school, distance learners are challenged to increase their meta-ability incorporating meta-cognitive, meta-affective, and meta-social ability as well as their learner-teacher relationship via $\mathrm{CMC}[3]$. Nonetheless, few empirical studies have revealed the critical issue, as the teaching and learning process primarily relied on FtF communication before the COVID-19 crisis. From the learner's perspective, this suggests that the distance educators should investigate the impact of a full online-learning format on meta-ability and interpersonal relations with them. Yet, there is no academic evidence published on this research topic. By identifying the knowledge gap in association with the sudden changeover to online education, this study proposes two research questions: In the COVID-19 situation, (i) does the full distance-learning method via CMC affect the learner's meta-ability? (ii) do the changes in meta-ability influence the learner-teacher relationship?

This research aims to investigate the impact of changes in the learner's meta-ability on interpersonal relations with teachers and examine a causal relationship across the variables. To do this, it proposes a new conceptual model presenting changes in a three-set learner's meta-ability and the learner-teacher relationship based on two CMC-related grand theories. This empirical study is meaningful because it differs from the prior literature in that the researchers examine the impact of the learner's meta-ability changes on interpersonal relations with teachers within the $\mathrm{CMC}$ context. The new theoretical paradigm is also valuable for distance educators and practitioners whose research interests include the learner's meta-ability, adding a practical significance to the body of knowledge in the CMC arena. In the 'new normal' era after the pandemic, this work will contribute to finding diverse alternative methods via CMC for improving the learner's social interaction with teachers.

\section{Theoretical Background}

\subsection{Computer-mediated Communication}

Higher education students need the frequent use of computers and the broader application of CMC in the instructional and educational setting[9]. CMC is defined as text, audio, and video exchanges between individuals through computers and a network connection[10]. It has become an integral form of communication for distance-learning and interpersonal relationships[11][12]. Due to the rapid development of $\mathrm{CMC}$, face-to-face (FtF) instruction has shifted to a distance-learning format in higher education[9]. Technologies in the higher education settings on CMC are based on synchronous and asynchronous modes of communications, as well as a mixture of media. Synchronous channels include instant chat rooms, voice over phonelines, and real-time video lectures. Whereas asynchronous channels cover discussion boards, bulletin boards, social networks, university weblogs, and text messages/e-mail that are non-interactive, occurring at different times[13]. Educators within universities are interested in improving the relationships between the use of the various technologies, students' learning experiences and students' expectations on the media type, preferences, and satisfaction with the class, also the reflections from their lectures through the $\mathrm{CMC}$ channels. Some researchers state that synchronous CMC interaction impacted students' expectations and comfort levels in online courses using more than asynchronous communication[9].

While there are multiple theoretical approaches to the qualities of $\mathrm{CMC}$, this research focuses on persuasion from the two theoretical perspectives of the media richness (MR) theory and the social 
information processing (SIP) theory. From the cues-filtered-out perspective, the MR theory is one of the CMC-specific theories; it asserts that various media differ in the number of cue systems inherent within them, and systematic reductions in the nonverbal cues conveyed by different channels lead to impersonal orientations among CMC users, although CMC media may reduce ambiguity. In addition, when confronted with a persuasive attempt, the presence/absence of nonverbal cues can lead people to engage in cognitively different processes. The MR theory thus proposes that the medium differs in richness or the ability of information to change understanding within a time interval[12]. From the interpersonal adaptation perspective, the SIP theory of CMC is a widely-used framework to tell differences between FtF communication and text-based CMC. It seeks to explain how CMC users may develop relations in a timely manner with others online, and the links achieve the level of development that is expected via FtF. The SIP theory articulates the assumption that communicators are motivated to develop interpersonal impressions and affinity regardless of media types. The theory also argues that nonverbal CMC media operate at a different rate from FtF depending on CMC users' ability as CMC functions require a longer time to occur between users[12].

\subsection{Meta-ability and Interpersonal Relations}

According to the SIP and MR theories, FtF communication, which provides a high social presence in the classroom, the speed of feedback from teachers, and the exchange of rich information between students and teachers, has been understood as the most effective manner for student-centric education [14]. Due to limited nonverbal cues, on the contrary, the recent widespread use of CMC in learning has asked students to develop an individual's meta-ability, thereby increasing critical interpersonal relations with teachers. Meta-ability is one of the underlying acquired abilities, which plays a significant role in enabling a wider range of academic knowledge and practical skills to be used effectively for learning [15]; the importance of meta-level ability in higher education learners has been discussed in the arena of self-motivated learning, self-directed learning, and social skills for specific situations on campus[16].

Meta-abilities are necessary for university students in the FtF class settings; they mainly include metacognitive ability (i.e., cognitive competencies about cognition that help students comprehend critical situations, recognize nonverbal cues, and sort out learning problems), meta-affective ability (i.e., capabilities in creating affect about affect by thinking about feelings of others and reflecting on the links between emotions), and meta-social ability (i.e., qualities in switching social attentions from each other outwards to the wider discourses and complying with the social scenarios in interactive class settings) [3]. Meta-cognitive ability allows students to regulate the cognitive process for themselves, such as planning their study, monitoring learning issues, and allocating time/effort, whereas meta-affective ability is to coordinate knowledge about how affect works and to reflect an awareness of feelings and emotional experience[17]. Meta-social ability is also important to maintain interpersonal relationships with others on campus by exchanging socioemotional messages in a timely fashion[12][18].

Literature related to meta-ability and interpersonal relations in the context of CMC arguably discusses the roles and contributions of CMC both positively and negatively. CMC enables the medium users not only to improve interpersonal relationships with both distant people and those nearby and to increase community belongingness irrespective of time and distance, but also to improve potential metacognitive and meta-affective knowledge by means of synchronous text-based media (e.g., real-time video conferencing) and/or asynchronous text-based media (e.g., discussion boards chatting) regardless of costs and socio-context[10]. On the other hand, CMC is more effortful for learners to do academic tasks than FtF, where the communication is intuitive[12]. It has even been understood that in studying via $\mathrm{CMC}$, it is almost impossible for most learners to raise three kinds of meta-abilities and a close learner-teacher relationship because traditional learning has relied on the FtF interactions in classroom settings[3]. Furthermore, interpersonal relationships by FtF contribute to an individual's academic 
achievement, but through CMC media, there is a minor positive impact on social adjustment and adaptation across learners and teachers[10].

\section{Research Design and Methods}

\subsection{Theoretical Model and Hypotheses}

Using CMC in higher education classes is one of the major interests in the field of education informatics and information systems. According to the extant literature related to the use of CMC in a learning context, most research on $\mathrm{CMC}$ focuses on general insights into the nature of $\mathrm{CMC}$, the need for $\mathrm{CMC}$ methods, the public use of $\mathrm{CMC}$ with distance-learning solutions, student motivations for using $\mathrm{CMC}$ media, and organizational motivation for adopting $\mathrm{CMC}$ technologies while a few empirical studies investigated the influence of CMC on interpersonal attraction[14][19]. Moreover, empirical research on changes in meta-ability and the impact on interpersonal relations via CMC has been rare [3][10]. Therefore, a new research model that can explain the unknown CMC-related phenomena should be developed to resolve previous contradictory findings of the effectiveness and utilization of CMC in the context of higher education[12]. Hence, this study comes up with a new conceptual framework shown in [Fig. 1] by relying on the MR theory and the SIP theory that support theoretical approaches to $\mathrm{CMC}$, meta-ability and interpersonal relations.

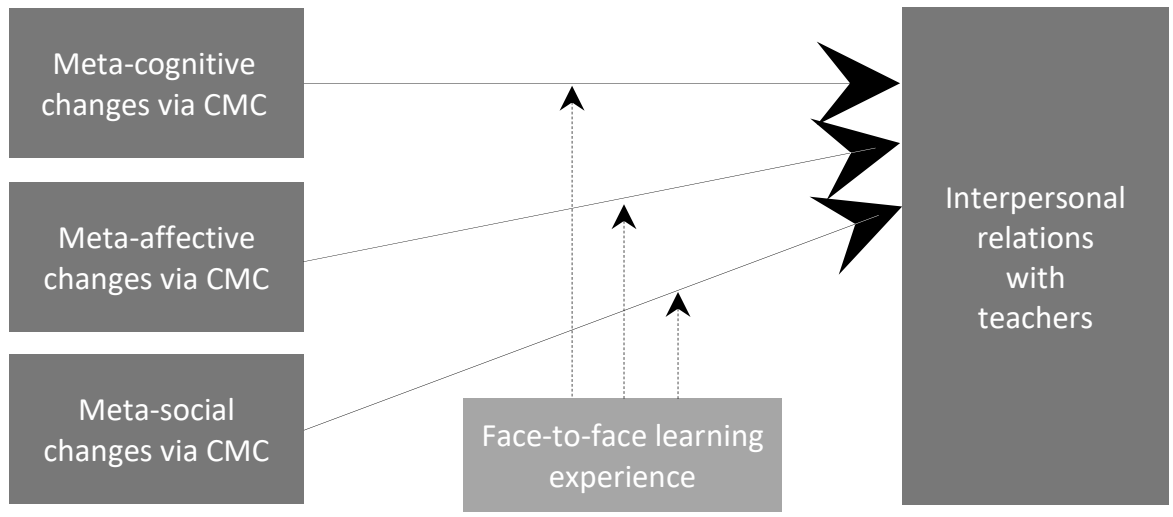

[Fig. 1] Conceptual Framework for the Study

From the learner's perspective rather than that of the teacher, the framework is designed to explain a causal relationship between changes in meta-ability (CMA) with three elements, the moderating effect by FtF learning experience and the impact on the learner-teacher relationship (LTR) via CMC within the higher education contexts. In a similar vein, the constructs and definitions in a three-fold breakdown of the learner's meta-ability changes and the interpersonal relationship with teachers are arranged for this study (see [Table 1]). All conceptual pre-determined variables presented in the table are employed for analyzing secondary data and survey questionnaires accordingly. This work also suggests the following four theoretical hypotheses based on the former studies of the MR and SIP theories so that it enables to examine the conceptual model and the constructs within the framework.

H1: The learner's meta-cognitive changes via CMC affect the learner-teacher relationship.

H2: The learner's meta-affective changes via CMC affect the learner-teacher relationship.

H3: The learner's meta-social changes via CMC affect the learner-teacher relationship.

H4: The learner's prior experiences in distance-learning mediate the learner-teacher relationship. 
[Table 1] Meta-ability and Interpersonal Relationship: Constructs/Variables used in the Study

\begin{tabular}{|c|c|c|c|}
\hline Construct & Description & Pre-determined variable & Literature \\
\hline \multirow{4}{*}{$\begin{array}{l}\text { Meta-cognitive } \\
\text { (MC) } \\
\text { Ability }\end{array}$} & \multirow{4}{*}{$\begin{array}{l}\text { Cognition about cognition; ability } \\
\text { in planning a learning task by } \\
\text { managing knowledge and } \\
\text { recognizing learning issues and } \\
\text { solutions }\end{array}$} & Learning plan (MC1) & \multirow{4}{*}[2]{$[16][18][20][21]$} \\
\hline & & Knowledge management (MC2) & \\
\hline & & Problem recognition (MC3) & \\
\hline & & Problem solving (MC4) & \\
\hline \multirow{4}{*}{$\begin{array}{l}\text { Meta-affective } \\
\text { (MA) } \\
\text { Ability }\end{array}$} & \multirow{4}{*}{$\begin{array}{l}\text { Affect about affect; ability in } \\
\text { thinking about the direction of } \\
\text { one's feelings and reflecting on the } \\
\text { links between emotions }\end{array}$} & A sense of closeness (MA1) & \multirow{4}{*}[1]{$[22][23][24]$} \\
\hline & & A sense of unity (MA2) & \\
\hline & & A sense of trust (MA3) & \\
\hline & & A sense of respect (MA4) & \\
\hline \multirow{4}{*}{$\begin{array}{l}\text { Meta-social } \\
\text { (MS) } \\
\text { ability }\end{array}$} & \multirow{4}{*}{$\begin{array}{l}\text { An individual's social skills and } \\
\text { process in switching attention to } \\
\text { each other to the wider discourses } \\
\text { and matching the specific social } \\
\text { scenarios }\end{array}$} & Mutual interaction (MS1) & \multirow{4}{*}[3]{$[4][18][25]$} \\
\hline & & Information processing (MS2) & \\
\hline & & Opinion exchanging (MS3) & \\
\hline & & Understanding of relation (MS4) & \\
\hline \multirow{4}{*}{$\begin{array}{l}\text { Interpersonal } \\
\text { relations } \\
\quad(\text { IR) }\end{array}$} & \multirow{4}{*}{$\begin{array}{l}\text { A social connection between } \\
\text { individuals in the classroom or } \\
\text { online by exchanging identity and } \\
\text { emotion via verbal and nonverbal } \\
\text { content }\end{array}$} & Social presence via CMC (IR1) & \multirow{4}{*}[3]{$[10][12][26][27]$} \\
\hline & & Social emotion via CMC (IR2) & \\
\hline & & Social identity via CMC (IR3) & \\
\hline & & Social satisfaction via CMC (IR4) & \\
\hline
\end{tabular}

\subsection{Research Methods}

\subsubsection{Multimethod Data Collection}

This study carried out data collection with S-university in Cheonan, Korea in December 2020 and June 2021 for two semesters; the intention of the data gathered twice in the interval of six months was to reflect the unexpected paradigm shifts into distance-learning for the duration of COVID-19. With a multimethod technique, this work combined information from two data sources to ensure validity and reliability for examining the new conceptual model: messages from e-Campus (where students and teachers exchange asynchronous texts via $\mathrm{CMC}$ ) of S-University, and primary data from survey participants attending the university. Based on available sampling, it collected 134 nonverbal messages from 117 students first to establish whether three meta-ability elements around the university students would exist. Then, provisional coding in accordance with 16 pre-determined variables (refer to [Table 1]) was undertaken, followed by content analysis that combines measurement techniques involving the systematic counting of the content in the communication messages[13]. Prior to the main survey, this step was necessary to raise the validity of the outcome since the [Fig. 1] framework had yet to be examined. As shown in [Table 2], the matrix scores from data analysis were able to identify sufficient content validity of meta-cognitive (MC), meta-affective (MA), and meta-social (MS) ability from the eCampus messages. Because the MC, MA, and MS constructs were confirmed by analyzing the text messages within the e-Campus, the research was allowed to move on to the subsequent surveys.

This work continued to conduct a two-phase online survey with a total of 207 undergraduate students attending S-university in line with the judgment sampling method of the researchers with expertise in CMC and online education: 102 respondents from six majors in December 2020 and 105 respondents from seven majors in June 2021. Between the students and their teachers, there was a mix of both synchronous and asynchronous communication channels during the full-scale of online education under the COVID-19 crisis. Each of the two conducted electronic surveys was structured with six sections to gather evidence from the S-university students in relation to (i) differences in learning between CMC and $\mathrm{FtF}$, (ii/iii/iv) three meta-ability elements, (v) interpersonal relations via CMC, incorporating 24 detailed questions in five-point Likert scales, and (vi) a set of demographic information about the survey 
participants. This study distributed the same set of questionnaires in two rounds of the survey to keep consistency in coding survey data. Six international students were not included from the data analysis stage, based on the advice from academic mentors in communicology, because answering consistently to the survey questions in the Korean language was challenging for them in nature.

[Table 2] Content Analysis: Matrix Scores on 3 Meta-abilities from the e-Campus Messages [ $N=134]$

\begin{tabular}{|c|c|c|c|c|c|}
\hline Elements & Variables & \multicolumn{2}{|c|}{ Frequency } & Occupation (\%) & Share $(\%)$ \\
\hline \multirow{4}{*}{$\begin{array}{c}\text { Meta-cognitive (MC) } \\
\text { Ability via CMC }\end{array}$} & MC1 & 8 & \multirow{4}{*}{59} & 13.6 & \multirow{4}{*}{44.0} \\
\hline & $\mathrm{MC} 2$ & 17 & & 28.8 & \\
\hline & MC3 & 10 & & 16.9 & \\
\hline & MC4 & 24 & & 40.7 & \\
\hline \multirow{4}{*}{$\begin{array}{l}\text { Meta-affective (MA) } \\
\text { Ability via CMC }\end{array}$} & MA1 & 27 & \multirow{4}{*}{49} & 55.1 & \multirow{4}{*}{36.6} \\
\hline & MA2 & 7 & & 14.3 & \\
\hline & MA3 & 10 & & 20.4 & \\
\hline & MA4 & 5 & & 10.2 & \\
\hline \multirow{4}{*}{$\begin{array}{l}\text { Meta-social (MS) } \\
\text { Ability via CMC }\end{array}$} & MS1 & 5 & \multirow{4}{*}{26} & 19.2 & \multirow{4}{*}{19.4} \\
\hline & MS2 & 10 & & 38.5 & \\
\hline & MS3 & 2 & & 7.7 & \\
\hline & MS4 & 9 & & 34.6 & \\
\hline
\end{tabular}

\subsubsection{Ethical Considerations}

This empirical study adopted typical quantitative skills in analyzing primary data and looked into human behaviors via CMC. Therefore, it ensured that ethical standards were maintained by enabling voluntary and anonymous respondents to participate in a survey for this pure academic work; the procedure of ticking off a six-line consent form prior to the two online surveys made sure that there would be neither ethical conflict nor privacy issues in processing survey data between the voluntary participants in this scholarly research and these authors while the research involving human subjects for the duration of the study. All the raw data collected from online sources have securely been stored in electronic form and available only for these researchers until the research publication.

\subsubsection{Research Instruments}

[Table 3] presents the descriptive statistics in relation to the sample of distance-learning students.

[Table 3] Descriptive Analysis: Demographic Information about the Survey Participants [ $N=207]$

\begin{tabular}{|c|c|c|c|}
\hline \multirow{2}{*}{ Attribute } & Sub-attribute & Frequency & Occupation (\%) \\
\hline \multirow{3}{*}{ Faculty/School } & Literature \& Social Sciences & 159 & 76.8 \\
\cline { 2 - 4 } & Natural Sciences \& Engineering & 25 & 12.1 \\
\cline { 2 - 4 } & Art \& Music \& Sports & 23 & 11.1 \\
\hline \multirow{2}{*}{ Gender } & Male & 62 & 29.9 \\
\cline { 2 - 4 } & Female & 145 & 70.1 \\
\hline \multirow{3}{*}{$\begin{array}{c}\text { Academic year } \\
\text { (Undergraduate) }\end{array}$} & First-year & 62 & 30.0 \\
\cline { 2 - 4 } & Second-year & 33 & 39.9 \\
\hline \multirow{2}{*}{$\begin{array}{c}\text { Prior experience in } \\
\text { FtF classes }\end{array}$} & Third-year & 31 & 15.0 \\
\cline { 2 - 4 } & Fourth-year & 63 & 30.4 \\
\hline
\end{tabular}


Among the 207 survey respondents attending S-University, the majority were undergraduate students in Literature \& Social Sciences (76.8\%), female participants (70.1\%), and first- and third-year students (69.1\%). In particular, the 144 students (69.6\%) were inexperienced in the FtF class settings in their campus life under the nationwide COVID-19 situation. To test the given four theoretical hypotheses, three underlying quantitative analyses, including reliability analysis, correlation analysis, and regression analysis, were undertaken in three steps after the descriptive analysis. The researchers and data analyzers utilized the Google Spreadsheet and MS-Excel 365 Spreadsheet for content analysis and IBM SPSS ${ }^{\circledR}$ Statistics 25 for reliability/correlation tests as well as IBM SPSS ${ }^{\circledR}$ Statistics 26, together with the PROCESS macro 3.5.3[28], that was effectively used for the following multiple regression analyses.

\section{Results}

First, the most common criteria of the reliability level are drawn in [Table 4] by conducting a reliability analysis for the evaluation of the data reliability on 24 survey questionnaires.

[Table 4] Inter-item Reliability: Variables in Meta-ability and Interpersonal Relations from Survey

\begin{tabular}{|c|c|c|c|c|c|}
\hline Construct & \multicolumn{2}{|c|}{ Inquires in survey } & $M$ & $S D$ & Cronbach's alpha $(a)$ \\
\hline \multirow{4}{*}{$\begin{array}{c}\text { Differences in } \\
\text { learning between } \\
\mathrm{CMC} \text { and } \mathrm{FtF} \\
{[N=63]}\end{array}$} & \multicolumn{2}{|c|}{ CF1 (Interest) } & 3.15 & 1.0389 & \multirow{4}{*}{$0.849 \sim 0.850$} \\
\hline & \multicolumn{2}{|c|}{ CF2 (Feeling) } & 2.89 & 1.0011 & \\
\hline & \multicolumn{2}{|c|}{ CF3 (Attitude) } & 3.24 & 0.9332 & \\
\hline & \multicolumn{2}{|c|}{ CF4 (Understanding) } & 2.91 & 1.0010 & \\
\hline \multirow{4}{*}{$\begin{array}{c}\text { Changes in } \\
\text { meta-cognitive (MC) } \\
\text { ability via CMC }\end{array}$} & $\mathrm{MC} 1$ & \multirow{20}{*}{$\begin{array}{l}\text { Refer to } \\
{[\text { Table 1] }}\end{array}$} & 3.56 & 0.9007 & \multirow{4}{*}{$0.838 \sim 0.842$} \\
\hline & $\mathrm{MC} 2$ & & 3.62 & 0.8885 & \\
\hline & MC3 & & 3.22 & 0.9078 & \\
\hline & MC4 & & 3.21 & 0.8924 & \\
\hline \multirow{4}{*}{$\begin{array}{c}\text { Changes in } \\
\text { meta-affective (MA) } \\
\text { ability via CMC }\end{array}$} & MA1 & & 2.97 & 0.9599 & \multirow{4}{*}{$0.843 \sim 0.846$} \\
\hline & MA2 & & 3.04 & 0.9392 & \\
\hline & MA3 & & 2.86 & 0.9301 & \\
\hline & MA4 & & 2.81 & 0.9391 & \\
\hline \multirow{4}{*}{$\begin{array}{c}\text { Changes in } \\
\text { meta-social (MS) } \\
\text { ability via CMC }\end{array}$} & MS1 & & 3.26 & 0.9488 & \multirow{4}{*}{$0.838 \sim 0.843$} \\
\hline & MS2 & & 3.20 & 0.9525 & \\
\hline & MS3 & & 3.21 & 0.9313 & \\
\hline & MS4 & & 2.97 & 0.8753 & \\
\hline \multirow{8}{*}{$\begin{array}{l}\text { Interpersonal } \\
\text { Relations (IR) } \\
\text { via CMC }\end{array}$} & Verbal 1 & & 2.97 & 0.6924 & \multirow{4}{*}{$0.848 \sim 0.851$} \\
\hline & Verbal 2 & & 2.89 & 0.6913 & \\
\hline & Verbal 3 & & 3.06 & 0.4991 & \\
\hline & Verbal 4 & & 3.05 & 0.7321 & \\
\hline & Nonverbal 1 & & 2.83 & 0.7854 & \multirow{4}{*}{$0.847 \sim 0.849$} \\
\hline & Nonverbal 2 & & 2.75 & 0.7911 & \\
\hline & Nonverbal 3 & & 2.94 & 0.5630 & \\
\hline & Nonverbal 4 & & 2.81 & 0.7229 & \\
\hline
\end{tabular}

† Cronbach's alpha for all 24 items: 0.846 ‡ MC/MA/MS: Independent variables, IR: Dependent variable

The overall results indicate a highly reliable degree for all response scales as a Cronbach's alpha coefficient of 0.80 or higher appeared to be a robust measure of scale reliability and internal consistency. In terms of the pre-inspection of a difference in learning between $\mathrm{CMC}$ and $\mathrm{FtF}, 63$ respondents (refer to the final attribute and its frequency on 'Yes' in [Table 3]) answered that 'interest in classes' as well as 'attitude in classes' is between the score range 3.15 and 3.24 while 'feeling in classes' and 'understanding 
of classes' appear at 2.89 and 2.91 respectively. These outcomes imply that the students showed a remarkable difference in $\mathrm{CF} 1$ (Interest) and CF3(Attitude) between the classes via CMC and FtF, given that CF1 and CF3 were scaled in-between 3 (Moderate) and 4 (Strong) whereas CF2 (Feeling), as well as CF4 (Understanding), was scaled toward 2 (Weak).

The inter-item reliability test uncovered that the mean average score of each independent variable with high reliability in meta-ability stays at 3.21 3.62 for changes in MC ability (learning plan; knowledge management; problem recognition; problem-solving), 2.81 3.04 for changes in MA ability (a sense of closeness; a sense of unity; a sense of trust; a sense of respect), and 2.97 3.26 for changes in MS ability (mutual interaction; information processing; opinion exchanging; understanding of relation). All four variables in MC ability exceeded 3 (Moderate) in scale, reaching up to 3.62. Thus, this study discovered that MC ability changes via CMC were strongly identified from the respondents among three meta-ability elements. As for IR incorporating social presence; social emotion; social identity; and social satisfaction through the verbal/nonverbal CMC media, each reliability for the scale shown in the students was highly satisfactory, and also six inquiries, including all four nonverbal items, related to the learner-teacher relationship via CMC were scaled toward 2 in scale (Weak).

Next, this research executed the bivariate correlations to measure how the variables between MC/MA/MS and IR were in a linear relationship and compute Pearson's coefficient $(r)$ with its significant level. Based on the results of correlation analysis, the variables with Pearson's $(r)$ only at the 0.01 level were selected for the following regression analysis to draw the cause-effect conclusions in the conceptual framework. As a result, shown in [Table 5], the variables of MC1 and MC2 with six scores (Verbal 2/3 and Nonverbal 1/2/3) of IR were positively correlated $(0.388<r<0.455)$, and the variables of MA1, MA3, and MA4 with four of the IR scores (Verbal 1/2 and Nonverbal 1) appeared a positive correlation $(0.387<r<0.407)$ at the two-tailed p-value respectively.

[Table 5] Correlation Analysis: Variables across Meta-ability and Interpersonal Relations

\begin{tabular}{|c|c|c|c|c|c|c|c|c|c|}
\hline \multirow{2}{*}{ Constructs } & \multirow{2}{*}{ Variables } & \multicolumn{8}{|c|}{ Interpersonal relations (IR) } \\
\hline & & Verbal 1 & Verbal 2 & Verbal 3 & Verbal 4 & NVerbal 1 & NVerbal 2 & NVerbal 3 & NVerbal 4 \\
\hline \multirow{4}{*}{$\begin{array}{l}\text { Changes in } \\
\text { meta-cognitive } \\
\text { (MC) ability } \\
\text { via CMC }\end{array}$} & $\mathrm{MC} 1$ & 0.173 & $0.389^{* *}$ & 0.278 & 0.269 & $0.423^{* *}$ & $0.462^{* *}$ & $0.388^{* *}$ & 0.239 \\
\hline & $\mathrm{MC} 2$ & 0.147 & 0.291 & $0.392^{* *}$ & 0.278 & $0.455^{* *}$ & $0.389^{* *}$ & $0.390^{* *}$ & $0.340^{*}$ \\
\hline & MC3 & 0.198 & 0.221 & $0.361^{*}$ & 0.209 & 0.289 & 0.285 & 0.228 & 0.198 \\
\hline & MC4 & 0.295 & 0.245 & $0.298^{*}$ & 0.278 & 0.330 & 0.237 & 0.271 & 0.210 \\
\hline \multirow{4}{*}{$\begin{array}{l}\text { Changes in } \\
\text { meta-affective } \\
\text { (MA) ability } \\
\text { via CMC }\end{array}$} & MA1 & 0.259 & $0.387^{* *}$ & 0.289 & 0.302 & $0.407^{* *}$ & 0.203 & 0.205 & 0.182 \\
\hline & MA2 & 0.178 & 0.282 & $0.334^{*}$ & 0.209 & $0.350^{*}$ & $0.309^{*}$ & 0.260 & 0.209 \\
\hline & MA3 & $0.392^{* *}$ & $0.341^{*}$ & 0.268 & 0.222 & 0.201 & 0.209 & 0.180 & 0.176 \\
\hline & MA4 & $0.404^{* *}$ & $0.336^{*}$ & 0.209 & 0.241 & 0.189 & 0.175 & 0.221 & 0.123 \\
\hline \multirow{4}{*}{$\begin{array}{l}\text { Changes in } \\
\text { meta-social } \\
\text { (MS) ability } \\
\text { via CMC }\end{array}$} & MS1 & -0.095 & 0.089 & 0.102 & -0.015 & 0.245 & 0.154 & 0.114 & -0.005 \\
\hline & MS2 & 0.225 & 0.198 & 0.205 & 0.156 & 0.203 & 0.227 & 0.172 & 0.102 \\
\hline & MS3 & -0.140 & -0.005 & 0.165 & 0.005 & 0.129 & 0.176 & 0.079 & 0.153 \\
\hline & MS4 & 0.168 & 0.189 & 0.278 & 0.201 & 0.287 & 0.231 & 0.186 & 0.178 \\
\hline
\end{tabular}

$* p<0.05 ; * * p<0.01$, two-tailed. $\quad$ + NVerbal $=$ Nonverbal

Overall, however, these significant Pearson's coefficients stayed at the moderate-low levels. In contrast, there was no statistically significant linear relationship between any of the MS variables and all variables in IR regardless of verbal/nonverbal media. These results similarly corresponded to the outcomes of the previous content analysis using the secondary data set (i.e., the messages from SUniversity's e-Campus), showing that MC ability and MA ability were comparably higher in frequency 
than that of MS ability. In sum, this study discovered a statistically significant moderate-low correlation between the learner's changes in MC ability and MA ability and verbal/nonverbal IR with teachers via CMC from the surveyed students.

Lastly, this work carried out a series of simple linear regression tests to see a cause-effect relation across the silent variables, including a moderator, between MC/MA and IR (see [Table 6]). After computing the aforementioned significant variables at the 0.01 level into three newly combined variables as $\mathrm{MC}$ (i.e., $\mathrm{MC} 1+\mathrm{MC} 2$ ), MA (i.e., MA1+MA3+MA4), and IR (i.e., Verbal 1/2/3 + Nonverbal $1 / 2 / 3$ ), it ran regression analysis together with the SPSS PROCESS macro by selecting the Model 1 option (i.e., Simple Moderation) and inputting a moderator, Academic Year (AY).

[Table 6] Regression Analysis: Cause-effect between Meta-ability and Interpersonal Relations

\begin{tabular}{|c|c|c|c|c|c|c|c|}
\hline Case \#1 & IR: Y & MC: X & {$[N=20$} & & & & \\
\hline \multirow{2}{*}{ Summary } & & $\mathrm{R} \mid \mathrm{R}^{2}$ & MSE & $F$ & $d f 1$ & $d f 2$ & $p$ \\
\hline & \multicolumn{2}{|c|}{\begin{tabular}{l|l|l|}
0.4987 & 0.2487
\end{tabular}} & 0.2329 & 12.4709 & 3.0000 & 203.0000 & 0.0000 \\
\hline Model & \multicolumn{2}{|r|}{$B$} & $S E$ & $t$ & $p$ & LLCI & ULCI \\
\hline Constant & \multicolumn{2}{|r|}{4.7317} & 0.4778 & 9.9040 & 0.0000 & 3.7852 & 5.6782 \\
\hline $\mathrm{MC}(\mathrm{X})$ & \multicolumn{2}{|r|}{-0.5186} & 0.1624 & -3.1925 & 0.0018 & -0.8405 & -0.1968 \\
\hline $\mathrm{AY}(\mathrm{W})$ & \multicolumn{2}{|r|}{-0.7085} & 0.1366 & -5.1849 & 0.0000 & -0.9792 & -0.4378 \\
\hline Int_1 & \multicolumn{2}{|r|}{0.2191} & 0.0462 & 4.7446 & 0.0000 & 0.1276 & 0.3105 \\
\hline \multirow{2}{*}{$\begin{array}{c}\mathrm{MC}^{*} \mathrm{AY} \\
\left(\mathrm{X}^{*} \mathrm{~W}\right)\end{array}$} & \multicolumn{3}{|c|}{$\mathrm{R}^{2}$-change } & $F$ & $d f 1$ & $d f 2$ & $p$ \\
\hline & \multicolumn{3}{|c|}{0.1497} & 22.5112 & 1.0000 & 203.0000 & 0.0000 \\
\hline AY (W) & & Effect & $S E$ & $t$ & $p$ & LLCI & ULCI \\
\hline 2.0000 & & -0.0805 & 0.0838 & -0.9601 & 0.3391 & -0.2466 & 0.0856 \\
\hline 3.0000 & & 0.1386 & 0.0612 & 2.2653 & 0.0254 & 0.0174 & 0.2598 \\
\hline 4.0000 & & 0.3576 & 0.0687 & 5.2053 & 0.0000 & 0.2215 & 0.4938 \\
\hline Case \#2 & IR: Y & MA: X & {$[N=20$} & & & & \\
\hline \multirow{2}{*}{ Summary } & & $\mathrm{R} \mid \mathrm{R}^{2}$ & MSE & $F$ & $d f 1$ & $d f 2$ & $p$ \\
\hline & \multicolumn{2}{|c|}{$0.4877 \mid 0.2379$} & 0.2363 & 11.7552 & 3.0000 & 203.0000 & 0.0000 \\
\hline Model & \multicolumn{2}{|r|}{$B$} & $S E$ & $t$ & $p$ & LLCI & ULCI \\
\hline Constant & \multicolumn{2}{|r|}{4.5062} & 0.4572 & 9.8570 & 0.0000 & 3.6005 & 5.4119 \\
\hline MA (X) & \multicolumn{2}{|r|}{-0.4171} & 0.1519 & -2.7461 & 0.0070 & -0.7181 & -0.1162 \\
\hline $\mathrm{AY}(\mathrm{W})$ & \multicolumn{2}{|r|}{-0.7303} & 0.1479 & -4.9388 & 0.0000 & -1.0232 & -0.4373 \\
\hline Int_1 & & 0.2153 & 0.0484 & 4.4469 & 0.0000 & 0.1194 & 0.3113 \\
\hline \multirow{2}{*}{$\begin{array}{c}\text { MA*AY } \\
\left(\mathrm{X}^{*} \mathrm{~W}\right)\end{array}$} & \multicolumn{3}{|c|}{$\mathrm{R}^{2}$-change } & $F$ & $d f 1$ & $d f 2$ & $p$ \\
\hline & \multicolumn{3}{|c|}{0.1334} & 19.7746 & 1.0000 & 203.0000 & 0.0000 \\
\hline $\mathrm{AY}(\mathrm{W})$ & & Effect & $S E$ & $t$ & $p$ & LLCI & ULCI \\
\hline 2.0000 & & 0.0135 & 0.0739 & 0.1834 & 0.8549 & -0.1328 & 0.1599 \\
\hline 3.0000 & & 0.2289 & 0.0607 & 3.7693 & 0.0003 & 0.1086 & 0.3492 \\
\hline 4.0000 & & 0.4442 & 0.0813 & 5.4658 & 0.0000 & 0.2832 & 0.6053 \\
\hline
\end{tabular}

$\dagger$ Based on the Model 1 simple moderation and the native output display on the PROCESS macro and IBM SPSS [26]

While the regression tests for two case models shown within both summaries resulted in a statistical significance, the Case \#1 for IR = MC * AY (i.e., the upper [X*W] in Table 6) was significant, showing the explanatory power as nearly $15 \%\left(\mathrm{R}^{2}\right.$-change: 0.1497$)$. Specifically, changes in $\mathrm{MC}$ influenced IR, and AY acted as a moderator in the regression model that can be reported as $(F(3,203)=12.4709, p<$ $0.01)$. The MC's coefficient was -0.5183 and the AY's coefficient presented at -0.7085 while the relation 
can be addressed to be $(t(203)=-3.1925, p<0.01)$ and $(t(203)=-5.1849, p<0.01)$ respectively. The AY's moderating effect was identified in Int_1: $(F(1,203)=22.5112, p<0.01)$; it was significant at $p<$ 0.05 under $50 \%$ where the median was 3 . Likewise, the Case \#2 within IR = MA * AY (i.e., the lower $\left[\mathrm{X}^{*} \mathrm{~W}\right]$ in Table 6$)$ also appeared statistically significant, and its explanatory power was over $13 \%\left(\mathrm{R}^{2}\right.$ change: 0.1334$)$. Similarly to Case \#1, changes in MA affected IR, and AY turned out be a significant moderator, showing a relationship in $(F(3,203)=11.7552, p<0.01)$. Under $(t(203)=-2.7461, p<0.01)$, the coefficient of MA was -0.4171 ; the AY coefficient showed -0.7303 in a relation with $(t(203)=-$ 4.9388, $p<0.01)$. The AY's moderating effect was $(F(1,203)=19.7746, p<0.01)$, showing a significance at $p<0.05$ under 50\% (median: 3 ).

\section{Discussion on Findings}

\subsection{Research Framework and Hypotheses}

Based on the above analytic results, the conceptual model in [Fig. 1] can be thus completed as the [Fig. 2] framework where the changes in MC/MA ability influence LTR, and the AY factor (i.e., the years of attending the university) works as a moderator that affects the causal relation between MC/MA ability and LTR. In line with the underlying findings, this study should address that the first hypothesis, H1: The learner's meta-cognitive changes via CMC affect the learner-teacher relationship, is supported accordingly. Similarly, the second hypothesis, H2: The learner's meta-affective changes via CMC affect the learner-teacher relationship, is supported. The fourth hypothesis, H4: The learner's prior experiences in distance-learning mediate the learner-teacher relationship, is also supported. As aforesaid in the correlation results prior to the regression test, we demonstrated that the third hypothesis, H3: The learner's meta-social changes via CMC affect the learner-teacher relationship is not supported.

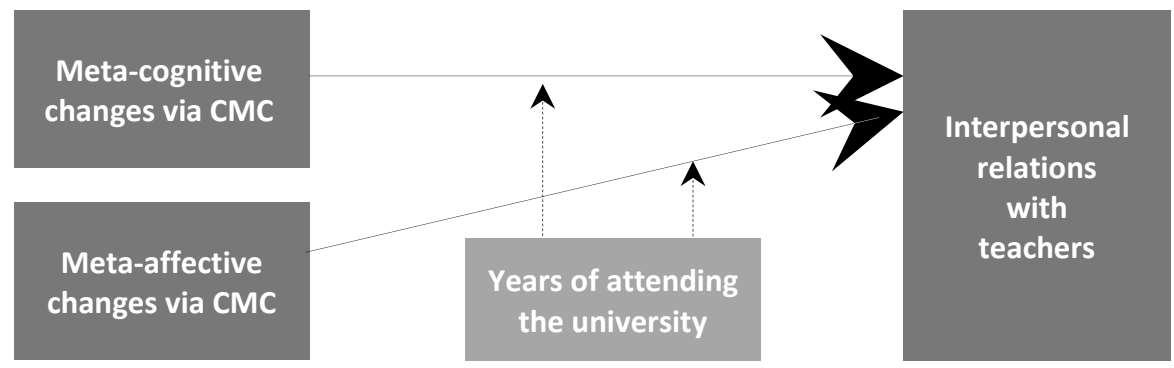

[Fig. 2] Research Framework based on the Findings

Consequently, under the COVID-19 situation, the full-distance learning method via CMC affects the learner's ability in planning a learning task by managing knowledge and recognizing solutions to the learning issues as well as thinking of the direction of their feelings by reflecting on the links between emotions; however, the impact of the learner's ability in mutual interaction, information processing, opinion exchanging, and understanding of relation on the learner-teacher relationship via CMC is unlikely[3]. Thereby, in accordance with the yearly period of attending the university, the learner's metaability makes a difference in a social connection between students and teachers communicating through the verbal and nonverbal CMC content[5][8]. Likewise, the theoretical lens of CMC within the study is able to answer two research questions and the research problems raised by the existing literature concerning CMC in different types (i.e., synchronous and asynchronous media) and LTR in higher education[15][16][19]. Besides, in the socio-context, the causal analysis shown in this paper can offer a better understanding of the multi-facet impact on Korean university students undergoing learning difficulties due to a full-scale online education during the COVID-19 pandemic[29][30]. 
As a whole, the key findings in the preceding section include a significant positive correlation between the learner's changes in meta-cognition ability as well as meta-affect ability and interpersonal relations in verbal/nonverbal modes with teachers via CMC. Of the three components on the learner's meta-ability, together with the moderation of the learner's AY that affects FtF learning experience, changes in meta-cognition and meta-affect influence the interpersonal relationship with teachers. These highlighted outcomes unearthing an actual cause-effect mechanism between the two meta-ability constructs are obviously different from the extant literature in that the improvement of meta-ability for students and establishment of a close interpersonal relationship with teachers via CMC may be feasible [3]. However, judging from the correlation at the moderate-low levels and the causal influence showing the low explanatory powers, this work sees that those activities can be challenging to both stakeholders within the research problem. Likewise, these empirical findings would be the critical significance of this study.

\subsection{Implications for Theory and Practice}

This article underlines the following implications based on the multiple insights: (i) It identified a remarkable response to the difference in learning between $\mathrm{CMC}$ and $\mathrm{FtF}$ in terms of interest in class and attitude in class via CMC during the COVID-19 situation; a full-scale online-learning format can generate an educational gap against FtF learning in the classroom in the aspect of drawing the higher education learner's attention to the classes via CMC. This research also implied that students' academic years with different experiences in the FtF classes might vary the educational gap. (ii) Teachers should find ways to let their students not only plan a learning task by managing knowledge themselves and recognizing learning issues but also think of the direction of feelings and reflect on the links between the learner-teacher emotions via the $\mathrm{CMC}$ media[31]. (iii) Both learners and teachers ought to consider making a social connection in an educational dimension between individuals in the classroom or online by exchanging identity and emotion via verbal/nonverbal content[27]. These implications will enable educators and policymakers to look into re-formatting an online education method under the pandemic situation further to improve meta-ability and interpersonal relations in higher education.

\section{Conclusion}

In response to improving the learner's meta-ability and interpersonal relationship with teachers in higher education during the COVID-19 pandemic, this research explains CMA and a learner-teacher relationship and asks whether a pure distance-learning method through media CMC affects the learner's meta-ability and the meta-ability changes influence the learner-teacher relationship through the realtime teaching and not simultaneous in time. Providing a new conceptual framework and collecting empirical data from a Korean university over two semesters, this study examines the given theoretical hypotheses using multiple quantitative analytic methods; its original CMC-specific research model will contribute to higher education academia and the field of education informatics in identifying the knowledge gap about CMC. In conclusion, teaching higher education learners through the CMC media may enhance their meta-ability, and learners and teachers are able to establish a close relationship with each other via synchronous and asynchronous communications.

This study has multiple main limitations. Firstly, the size/range of the data sample was practically limited by collecting survey answers online during the breaks from a university. Secondly, this paper was rooted in the view of learners to narrow down to the critical issue of the changeover to the onlinelearning format, not that of teachers in higher education. Thirdly, the data analysis included only domestic students due to the very limited number of international students whose understanding was unskilled in communication in Korean. Finally, by mapping out an initial model, this study relied on a 
simplified research structure in the Korean higher education context.

Therefore, future work would be required with more samples across the universities in South Korea and/or two different survey manners in two groups for international and domestic because a separate research design from the teacher's perspective would be insightful to fill the gap in this study. Also, since the coefficients in correlation tests and the adjusted r-squares in regression tests are low, the follow-up work might consider partially redesigning the formation of survey questionnaires on meta-ability and interpersonal relations to have a more significant impact on the variables. Lastly, the application of more advanced analytic skills, such as path analysis or structured equation modeling, together with additional dependent variables in the learner-teacher relationship other than a single variable set, may provide further in-depth findings in line with the proposed theoretical framework.

\section{References}

[1] W. H. Hwang, D. H. Lee, A meta-analysis on emotion and mathematics education research, Journal of the Korean School Mathematics Society, (2020), Vol.23, No.3, pp.351-375, DOI: 10.30807/ksms.2020.23.3.006

[2] D. Kim, S. La, H. E. Lee, A meta-analysis on the characteristics and effects of meta-cognitive strategic interventions in Korea: Comparison between group-designed studies and single case studies, Asian Journal of Education, (2016), Vol.17, No.3, pp.21-48, UCI: G704-000733.2016.17.3.014

[3] M. S. Ko, Education for the formation of personal relationships through computer-mediated communication: Focused on the philosophy of embodiment and emotion, Journal of Moral \& Ethics Education, (2012), No.36, pp.85-113, DOI: 10.18338/kojmee.2012..36.85

[4] H. Torrance, J. Pryor, Developing formative assessment in the classroom: using action research to explore and modify theory, British Educational Research Journal, (2001), Vol.27, No.5, pp.615-631, DOI: 10.1080/0141192012009578

[5] S. W. Han, B. Kim, A study on the response of learners to university online education after Corona 19, Culture and Convergence, (2020), Vol.42, No.10, pp.155-172, DOI: 10.33645/cnc.2020.10.42.10.155

[6] B. K. Lee, A study on learners' response to online college English class as general education due to the COVID-19 pandemic, Korean Journal of General Education, (2020), Vol.14, No.4, pp.97-112, DOI: 10.46392/kjge.2020.14.4.97

[7] C. Nam, M. Lee, J. Jeon, An exploration of a paradigm shift and development plans for career education in Busan for the post-COVID-19 era, Institute for Humanities and Social Sciences, (2021), Vol.22, No.3, pp.307-326, DOI: 10.15818/ihss.2021.22.3.307

[8] D. J. Lee, M. Kim, University students' perceptions on the practices of online learning in the COVID-19 situation and future directions, Multimedia-Assisted Language Learning, (2020), Vol.23, No.3, pp.359-377, DOI: 10.15702/mall. 2020.23.3.359

[9] J. P. William, H. L. Chen, Computer mediated communication and multimodal instruction in higher education, Handbook of Research on Computer Mediated Communication, IGI Global, (2008)

[10] Z. Cemalcilar, Communicating electronically when too far away to visit, Handbook of Research on Computer Mediated Communication, IGI Global, (2008)

[11] B. M. Okdie, R. E. Guadagno, Social influence and computer mediated communication, Handbook of Research on Computer Mediated Communication, IGI Global, (2008)

[12] J. B. Walther, Theories of computer-mediated communication and interpersonal relations, The SAGE Handbook of Interpersonal Communication, 4th ed., Sage Publications, (2011)

[13] R. J. Ocker, The impact of personality on virtual team creativity and quality, Handbook of Research on Computer Mediated Communication, IGI Global, (2008)

[14] Z. Guo, F. Tan, K. Cheung, Students' uses and gratifications for using computer-mediated communication media in learning contexts, Communications of the Association for Information Systems, (2010), Vol.27, No. 1, pp.339-378, 
DOI: $10.17705 / 1 C A I S .02720$

[15] Y. L. Kim, The mediating effect of ego-resilience on the relation between parental attitude perceived by adolescence and self-regulated learning ability, The Journal of the Korea Contents Association, (2018), Vol.18, No.10, pp.596-607, DOI: 10.5392/JKCA.2018.18.10.596

[16] M. Y. Cho, M. O. Chae, Impact of self-directed learning ability and metacognition on clinical competence among nursing students, The Journal of Korean Academic Society of Nursing Education, (2014), Vol.20, No.4, pp.513-522, DOI: $10.5977 / j k a s n e .2014 .20 .4 .514$

[17] W. Burleson, Affective learning companions: Strategies for empathetic agents with real-time multimodal affective sensing to foster meta-cognitive and meta-affective approaches to learning, motivation, and perseverance, Massachusetts Institute of Technology, Doctoral Dissertation, (2006), pp.2-158.

[18] B. Crossouard, Reforms to higher education assessment reporting: opportunities and challenges, Teaching in Higher Education, (2010), Vol.15, No.3, pp.247-258, DOI: 10.1080/13562511003740809

[19] M. L. Antheunis, P. M. Valkenburg, J. Peter, Computer-mediated communication and interpersonal attraction: An experimental test of two explanatory hypotheses, CyberPsychology \& Behavior, (2007), Vol.10, No.6, pp.831-836, DOI: $10.1089 / \mathrm{cpb} .2007 .9945$

[20] S. Park, S. Lee, M. Choi, A study on effects of well-structured cognitive reflection journal on metacognition and learning achievement, Journal of Engineering Education Research, (2008), Vol.11, No.1, pp.5-14, DOI: 10.18108/jeer.2008.11.1.5

[21] R. A. Sperling, B. C. Howard, L. A. Miller, C. Murphy, Measures of children's knowledge and regulation of cognition, Contemporary Educational Psychology, (2002), Vol.27, No.1, pp.51-79, DOI: 10.1006/ceps.2001.1091

[22] S. H. Kim, Delphi study on the concept and the teaching and learning methods of meta-affect in mathematics, The Journal of Educational Research in Mathematics, (2019), Vol.29, No.2, pp.321-338, DOI: 10.29275/jerm. 2019.5.29.2.321

[23] V. A. DeBellios, G. A. Goldin, Affect and meta-affect in mathematical problem solving: A representational perspective, Educational Studies in Mathematics, (2006), Vol.63, No.2, pp.131-147, DOI: 10.1007/s10649-006-9026-4

[24] A. C. Graesser, S. D'Mello, N. Person, Meta-knowledge in tutoring, Handbook of Metacognition in Education, Taylor \& Francis Group, (2009)

[25] K. Lund, Human support in CSCL: What we know about CSCL, Springer, (2004)

[26] J. Hong, A study on non-verbal communication through self-representation and symbol characteristics: Focus on SNS emoticons, Korean Journal of Communication Studies, (2016), Vol.24, No.3, pp.5-31, UCI: G704-001501. 2016.24.3.002

[27] E. J. Lee, Twitter as computer-mediated communication: Issues and future directions, Journal of Communication Research, (2011), Vol.48, No.1, pp.29-58, DOI: 10.22174/jcr.2011.48.1.29

[28] A. F. Hayes, Introduction to mediation, moderation, and conditional process analysis: A regression-based approach, Guilford publications, (2013)

[29] M. Y. Jo, J. W. Park, A study on the effect of a cooperative learning program using a social network service in education during the COVID-19 pandemic, Asia-pacific Journal of Convergent Research Interchange, (2021), Vol.7, No.6, (2021), pp.47-62, DOI: 10.47116/apjcri.2021.06.05

[30] S. Bae, Y. Jee, Y. Park, A study on experience of transition to online lecture due to COVID-19 in nursing students, Asia-pacific Journal of Convergent Research Interchange, (2021), Vol.6, No.12, pp.11-24, DOI: 10.47116/apjcri. 2020.12.02

[31] E. Kim, Interpersonal media choice patterns in a mediated interpersonal communication environment, Seoul National University, Doctoral Dissertation, (2017), pp.1-205. 